\title{
Clinical Value of Ultrasound-Guided Minimally Invasive Biopsy in the Diagnosis or Treatment of Breast Nodules
}

This article was published in the following Dove Press journal: Cancer Management and Research

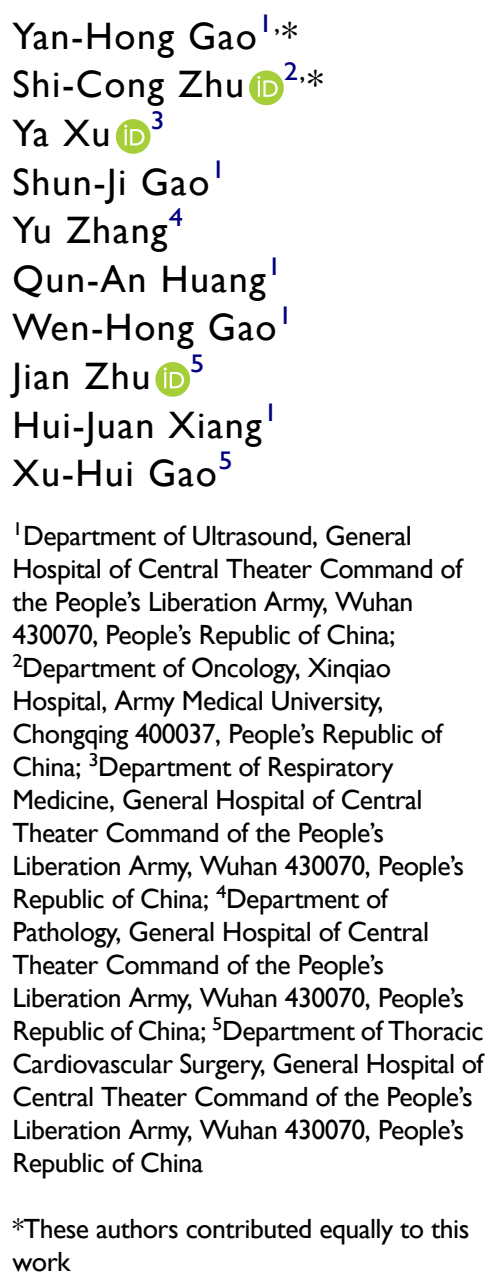

Correspondence: Xu-Hui Gao; Hui-Juan Xiang

General Hospital of Central Theater Command of the People's Liberation Army, 627\#, Wuluo Road, Wuchangqu, Wuhan, Hubei 430070, People's Republic of China

Tel +86-1387| I 66597

Fax +86-27-50772388

Email whzyygxh@I26.com; xhjyxr@I26. com
Purpose: To explore the clinical value of ultrasound-guided minimally invasive biopsy of breast nodules for diagnosis and treatment of patients with no positive clinical signs on manual breast examination.

Methods: We performed a retrospective review of 136 patients with no signs on breast palpation who underwent ultrasound-guided minimally invasive biopsy. A total of 63 patients underwent breast nodule resection from October 2018 to December 2019 at the General Hospital of Central Theater Command of the People's Liberation Army. Clinical data, including indications for minimally invasive biopsy or resection, pathological and surgical results were retrospectively analyzed.

Results: A total of 199 patients were studied; 136 underwent minimally invasive biopsy and 63 underwent resection. No severe surgical complications occurred. Minimally invasive biopsy of breast nodules was superior to resection with respect to operation time, incision length, and postoperative complication rate.

Conclusion: Ultrasound-guided minimally invasive biopsy of breast nodules is feasible for treatment of patients with negative breast nodules and can achieve accurate diagnosis and satisfactory resection.

Keywords: minimally invasive breast biopsy, diagnosis, breast nodules, benign breast masses

\section{Introduction}

Vigorous promotion has resulted in breast examinations becoming a routine part of health examinations for women. ${ }^{1}$ Substantial advances in ultrasound equipment and technology has allowed timely detection of small breast lesions at early stages. ${ }^{2,3}$ Suspicious malignant lesions not only cause physical discomfort but also cause substantial anxiety. ${ }^{4}$ The "Clinical Practice Guidelines in Breast Cancer by Chinese Anti-Cancer Association" recommend performing histopathological examinations following imaging examinations that reveal possible malignancies. ${ }^{5}$

The mammary gland is an organ unique to women. It is highly desirable to achieve satisfactory sampling, accurate diagnosis, and rapid recovery. For these reasons, minimally invasive resection of breast nodules has received widespread attention. ${ }^{6}$ At present, ultrasound-guided minimally invasive devices are mainly used for breast nodule biopsies. However, in China, the technique is also used to remove benign breast nodules. ${ }^{7}$ This practice has not been reported internationally. 
Therefore, we conducted an analysis of the clinical value of ultrasound-guided minimally invasive biopsy for breast nodules.

\section{Participants and Methods}

This retrospective study cohort included 136 patients with non-palpable breast nodules who were diagnosed on ultrasound with BI-RADS category 3 or category $4 \mathrm{a}$ with maximum diameters of $0.7-2.5 \mathrm{~cm}$. All patients underwent minimally invasive biopsy (hereafter referred to as the minimally invasive group). The 136 patients were all adult females, aged 18-69 years (mean $34 \pm 18.6$ years). Of these, 94 patients underwent unilateral minimally invasive biopsy of breast nodules (including 68 with single nodules and 26 with multiple nodules), and 42 were bilateral. There were 87 patients with reproductive history and 49 without any reproductive history.

A total of 63 patients with BI-RADS Class 3 or Class $4 \mathrm{a}$ breast nodules undergoing resection were randomly selected (hereafter referred to as the surgery group; a random number table was generated). The 63 patients were all adult women, aged 17-82 years (mean $32 \pm 18.9$ years). Of these, 41 underwent unilateral mammary nodule resection (including 32 with single nodules and 10 with multiple nodules), and 21 with bilateral nodules. There were 43 patients with reproductive histories and 20 without reproductive histories.

All patients were recruited within the same time (from October 2018 to December 2019) at the General Hospital of Central Theater Command of the People's Liberation Army. The surgeons determined the histopathological examination modalities, either ultrasound-guided minimally invasive biopsy or surgical resection, according to the Guidelines in Breast Cancer by the Chinese AntiCancer Association.

This study complied with the Declaration of Helsinki and was approved by the Ethics Committee of General Hospital of Central Theater Command of the Chinese People's Liberation Army (WJ2019H113, Wuhan, China).

\section{Minimally Invasive Biopsy}

We employed a GE Logiq E9 Doppler ultrasonic diagnostic apparatus with an ultrasound probe frequency of $10 \mathrm{MHz}{ }^{8}$ Operations were performed by breast surgeons in a laminar flow operating room. The patients were asked to lie supine, with their hands behind the heads or on the edge of the table. The ultrasound probe was placed directly above the breast nodules to clarify the location, size, shape, and distribution of the surrounding blood vessels to confirm consistency with the previous color Doppler ultrasound reports and to select and mark the puncture points. After routine disinfection and draping, local infiltration anesthesia was performed under ultrasound guidance. A total of $10-40 \mathrm{~mL}$ local anesthetic (a mixture of $10 \mathrm{~mL}$ lidocaine, $10 \mathrm{~mL}$ ropivacaine hydrochloride injection, and $20 \mathrm{~mL}$ saline) was injected around the lesion and the puncture channel to fully anesthetize the surgical field and adequately separate nodules from the surrounding tissues (Figure 1). This was done to facilitate the smooth insertion of the puncture cutter head. A bistoury was used to incise the skin at the puncture site (about $5 \mathrm{~mm}$ ) (Figure 2), and the puncture cutter was pushed forward while avoiding blood vessels under ultrasound guidance (Bard System, USA). The puncture cutter was placed into the bottom of the lesion by adjusting the entry position, and the ultrasound probe was rotated 90 degrees to observe the positional relationship between the puncture cutter and the nodules in the rightangle section. We opened the window-opening cutting system of the puncture cutter when it met the cutting requirements. The system used a vacuum source to apply negative pressure

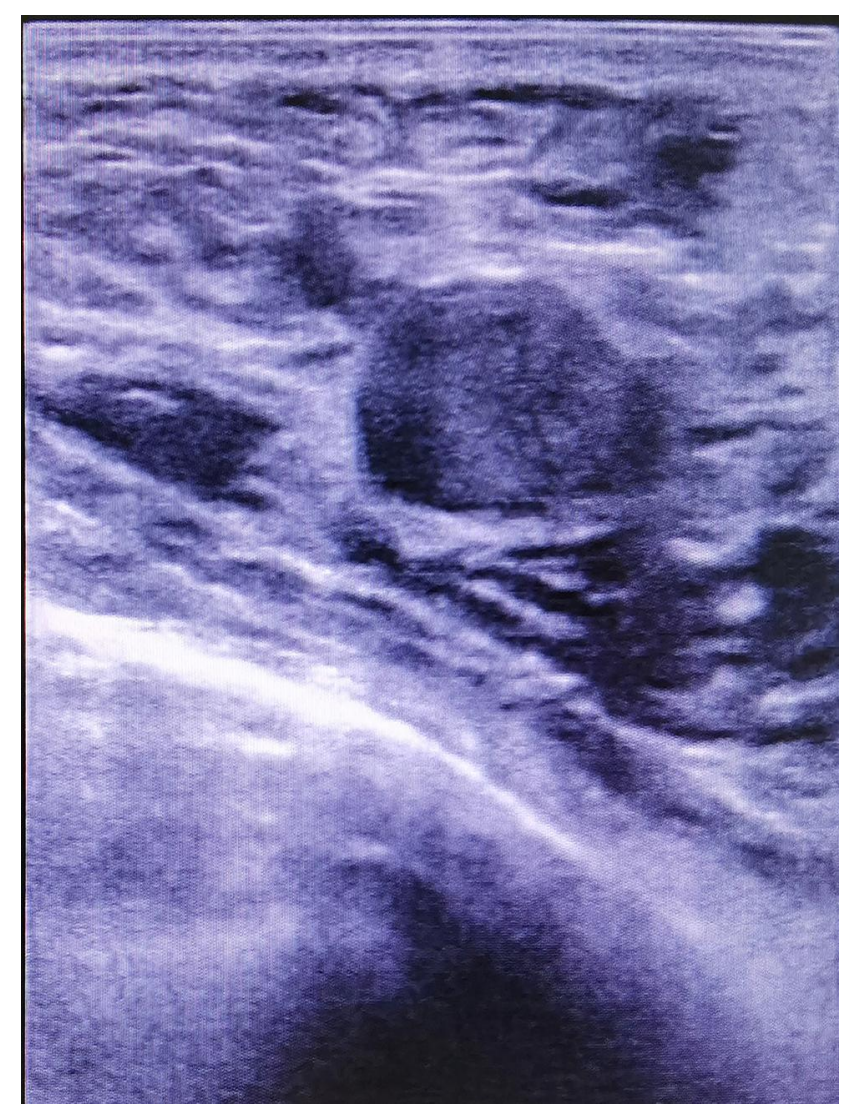

Figure I Anesthetics separated the nodule from the surrounding tissue during ultrasound-guided minimally invasive biopsy of breast nodules. 


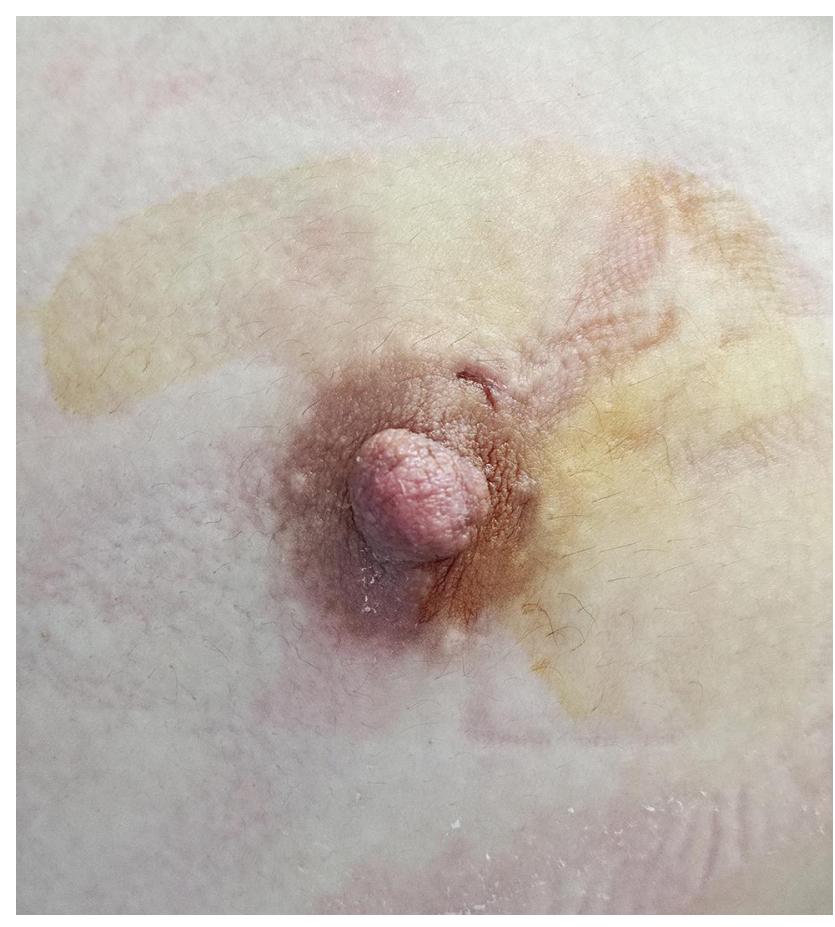

Figure 2 Incision of ultrasound-guided minimally invasive biopsy of breast nodules.

and aspirated the nodules into the groove. The relationship between the nodules and the cutting grooves of the puncture cutter was strictly observed under ultrasound. Then, the angle and depth of the knife were adjusted. Using repeated resections and suction, the nodules changed from large to small until they were removed entirely on ultrasound (the nodules showed signs of "sunset"), achieving the goal of complete resection of the lesion on imageology. When there were no residual nodules in the surgical field after ultrasonic investigation, the puncture cutter was slowly removed and ultrasound was performed again to detect residual nodules and bleeding. By injecting an appropriate amount of epinephrine-saline into the puncture point, the residual cavity was filled. Then, ultrasound was performed again to check for residual nodules (to prevent residual nodules from adhering to the wall and to determine whether there were residual hypoechoic nodules by comparing anechoic liquid area with the hypoechoic nodule area) and bleeding. Finally, the epinephrine-saline was expressed out, and a pressure dressing was applied to the puncture point.

\section{Assessment of Outcomes}

We recorded the indications for minimally invasive biopsy, pathological biopsy diagnosis, operation time, incision length, amount of intraoperative bleeding, patient satisfaction, and postoperative complications. The bleeding amount during the operation was calculated by a surgery nurse and an anesthesiologist according to the wetted area of ordinary gauze (a fully wetted gauze was recorded as $20 \mathrm{~mL}$ of bleeding, and 10 or $5 \mathrm{~mL}$ was recorded according to the wetted area), and the average value was taken as the final result. Patient satisfaction was based on the results of an unregistered questionnaire on the quality of medical care at the time of discharge. The questionnaire included the patient's estimation of the treatment effect, the degree of satisfaction with the surgeons, the degree of satisfaction with the nurse, and an evaluation of the ward environment. Postoperative complications included incisional infection, postoperative bleeding, and hematoma (no other complications occurred in this group).

\section{Statistical Analyses}

SPSS13.0 software (IBM Corp., Armonk, NY, USA) was used for all data analyses. All normally distributed measurement data and homogeneity variances were expressed as mean \pm standard deviation (SD). The Student's $t$-test was applied to compare differences among measurement data. The Chi-square test was used to compare differences among enumeration data. $p \leq 0.05$ denoted statistical significance.

\section{Results}

\section{Baseline Characteristics}

There were no statistically significant differences between the minimally invasive and surgery groups with respect to baseline characteristics, including age, number of breast nodules, and reproductive history $(p>0.05)$. The indications for minimally invasive biopsy were surgeon recommendation because the nodules were small (112 cases) and patient request for clarification of the nature of the nodules (24 cases). Indications in the surgery group were surgeon recommendation because the nodules were positive on palpation ( 55 cases) and patient request to clarify the nature of the nodules ( 7 cases). There was no significant differences between the groups $(p>0.05)$. The comparison of features of patients and lesions in both groups is shown in Table 1.

\section{Comparison of Operation Statuses and Complication Rates}

Operation time, incision length, bleeding amount, patient satisfaction, and postoperative complication rates in the 
Table I Comparison of Characteristics of Patients and Lesions

\begin{tabular}{|l|l|l|}
\hline Characteristics & Minimally Invasive Group & Surgery Group \\
\hline Cases & 136 & 63 \\
Age (years) & $18-69(34 \pm 18.6)$ & $17-82(32 \pm 18.9)$ \\
Size $(\mathrm{cm})$ & $0.7-2.5(1.2 \pm 8.2)$ & $1.5-3.7(2.5 \pm 10.6)$ \\
Palpable & Negative & Positive \\
\hline
\end{tabular}

minimally invasive group were significantly better than those of the surgery group $(p<0.05$; Table 2$)$.

\section{Minimally Invasive Biopsy of Breast Nodules}

Breast cancer suspected to be clinically malignant with negative palpation is the main indication for minimally invasive biopsy of breast nodules. It can also be considered for patients with breast nodules who have aesthetic requirements for breast incisions. When breast nodules are negative on palpation, but BI-RADS category 3 (high-risk factors) or category 4a breast is indicated on color Doppler ultrasound, biopsy should be considered to determine the pathological nature. If the nodule is non-palpable, it will significantly increase the difficulty of surgical exploration during the traditional resection of breast nodules. Because the breast nodules are relatively small, it is more difficult to detect the nodules after local infiltration anesthesia, and the pathologist often cannot even identify the nodules after resection. Minimally invasive biopsy of breast nodules can accurately remove the nodules under the guidance of imaging.

There were three patients with breast nodules found on health examination in which minimally invasive biopsy indicated breast cancer. For a typical patient, 42 years old, the breast color Doppler ultrasound suggested BI-RADS 4a nodules $(0.7 \mathrm{~cm} \times 0.3 \mathrm{~cm})$. The pathological results after minimally invasive biopsy showed intraductal papilloma, and two reactive hyperplastic lymph nodes were also seen (Figure 3). For patient 2, 45 years old, the color Doppler ultrasound showed BI-RADS 4a nodules $(0.8 \mathrm{~cm} \times 0.6 \mathrm{~cm})$.
The pathological results of the minimally invasive biopsy showed breast invasive breast cancer, ER (+), PR (+), Her-2 (-), Ki67 (+20\%) (Figure 4). For case 3, 42 years old, the breast color Doppler ultrasound showed BI-RADS type 3 nodules $(1.4 \mathrm{~cm} \times 0.8 \mathrm{~cm})$. The pathological results of the minimally invasive biopsy showed invasive breast cancer, ER (-), PR (-), Her-2 (1+), Ki67 (+60\%) (Figure 5).

\section{Discussion}

\section{The Importance of Ultrasound-Guided Minimally Invasive Biopsy of Breast Nodules}

In the case of small breast nodules, it is difficult for color Doppler ultrasound to classify the degree of benign and malignant breast nodules. Some breast nodules have shown to be BI-RADS type 3 or $4 a$ on color Doppler ultrasound examination may represent early breast cancer. ${ }^{9}$ In the present study, five patients were diagnosed with breast cancer in this group and the remaining patients were diagnosed with benign nodules and did not have breast cancer detected within 6 months after the biopsy.

The need for preventive medicine and early cancer screening and diagnosis is increasing and patients are demanding minimally invasive biopsy. ${ }^{10}$ For patients with family histories of breast cancer, it is difficult to tolerate the long-term presence of breast nodules. Minimally invasive biopsy can achieve complete resection based on imaging. ${ }^{11}$

Nodules in the breast ducts are usually small. If a nodule biopsy is necessary, mammary gland endoscopy is required prior to surgery (this examination is invasive and expensive). According to the results of this examination, the tissues are excised after methylene blue staining. Furthermore, the examination is invasive, which increases the difficulty of surgical exploration for nodules. ${ }^{12,13}$ In the first case, we showed that intraductal nodules were accurately removed by minimally invasive biopsy. The pathological nature was

Table 2 Comparison of Clinical Effects of the Surgical Methods

\begin{tabular}{|l|l|l|l|l|l|}
\hline & $\begin{array}{l}\text { Operation Time } \\
(\mathbf{m i n})\end{array}$ & $\begin{array}{l}\text { Incision Length } \\
(\mathbf{m m})\end{array}$ & $\begin{array}{l}\text { Bleeding } \\
\text { Amount }(\mathbf{m L})\end{array}$ & $\begin{array}{l}\text { Patient } \\
\text { Satisfaction }\end{array}$ & $\begin{array}{l}\text { Postoperative } \\
\text { Complications Rate }\end{array}$ \\
\hline $\begin{array}{l}\text { Minimally invasive group } \\
(\mathrm{n}=136)\end{array}$ & $16.5 \pm 5.2$ & $4.25 \pm 1.1$ & $8.6 \pm 4.5$ & $132(97.1 \%)$ & $2(1.5 \%)$ \\
Surgery group $(\mathrm{n}=63)$ & $25.1 \pm 7.1$ & $19.7 \pm 9.7$ & $6.6 \pm 3.2$ & $61(96.8)$ & $5(7.9 \%)$ \\
$t / \chi^{2}$ & 8.267 & 15.572 & 1.024 & 0.08 & 5.304 \\
$P$ & $<0.001$ & $<0.001$ & 0.767 & 1.000 & 0.034 \\
\hline
\end{tabular}




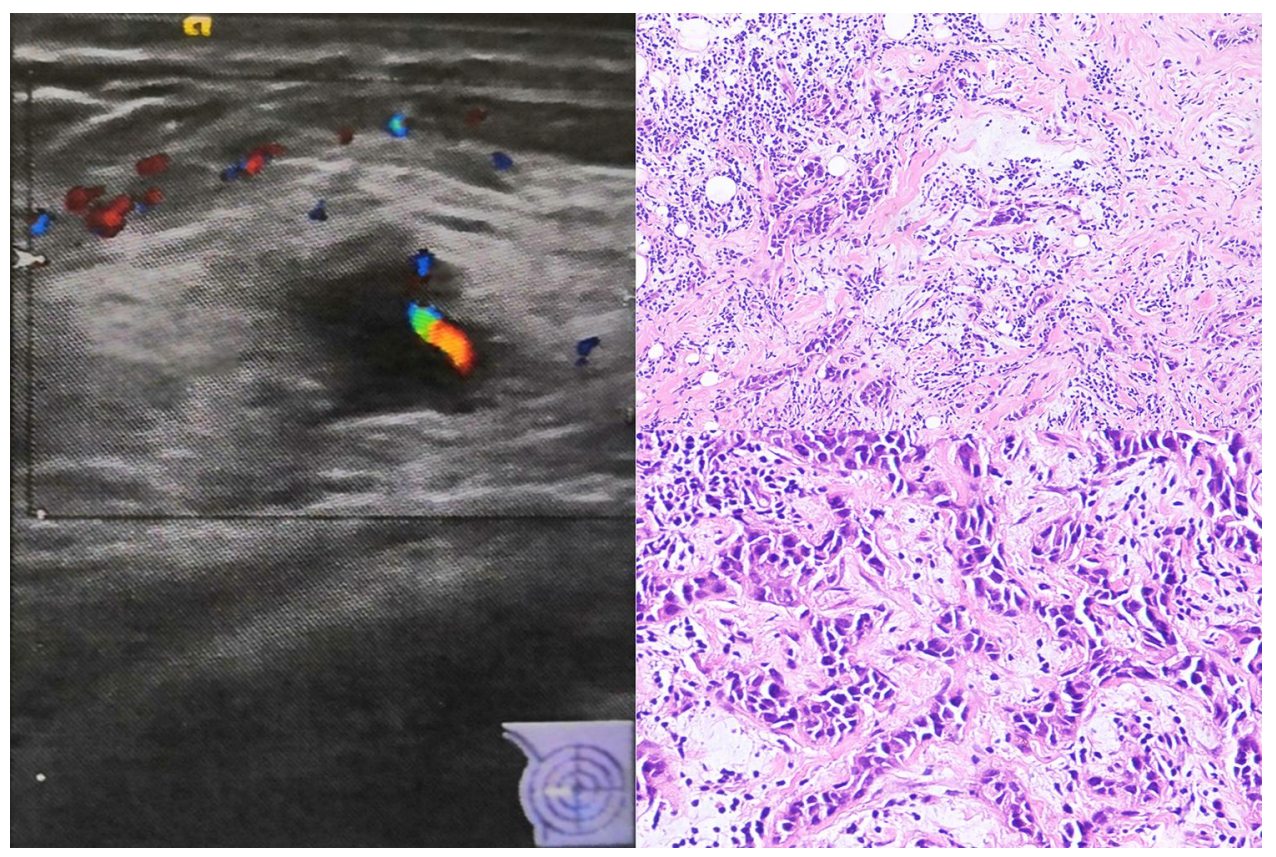

Figure 3 Color ultrasound examination of the breast revealing breast nodules of type BI-RADS 4A. Postoperative pathological results suggested intraductal papilloma and reactive hyperplasia of lymph nodes.

explicit, the size of the incision was smaller, and the clinical effect was superior.

\section{Advantages of Ultrasound-Guided Minimally Invasive Biopsy of Breast Nodules}

This method is minimally invasive and can be used to perform biopsy and resection of the lump through a smaller puncture port. ${ }^{14}$ It can perform biopsy and resection of nodules that are difficult to remove by traditional surgery. In clinical practice, breast nodules smaller than $1.5 \mathrm{~cm}$ are generally difficult to palpate and to locate in traditional procedures. ${ }^{15}$ Local anesthetics in the surgical field make it more difficult to detect the nodules during the operation. Therefore, more normal tissue or glands from a breast would be removed in traditional surgery. ${ }^{16}$ It is inconvenient to use ultrasound during traditional surgery because the incision is located directly above the nodule. ${ }^{17}$ It has been reported that methylene blue dye solution can be used for preoperative marking in traditional surgery. However, some nodules cannot be found during the operation. ${ }^{18}$ The ultrasound probe can be placed directly above the nodule during the ultrasound-guided minimally invasive biopsy of breast nodules. The surgical puncture point is usually located next to the probe. Ultrasound can be used to guide the insertion of the local infiltration anesthesia needle throughout the surgery. Local anesthetics can often separate the nodules from healthy breast tissue. Nodules can be removed from large to small until they disappear based on imaging. ${ }^{19}$

The minimally invasive procedure may reduce problems related to incisional infections. After the resection of nodules in traditional surgery, some nodules located deeply need to be treated with drainage sheets and they tend to leave sizeable postoperative incision scars. There is also a measurable probability of incisional infection for these shallow nodules. ${ }^{20}$ Although the outcomes are not poor, dressing changes are time-consuming, and this reduces patient satisfaction.

Traditional puncture technology obtains 1-3 thin linelike tissues that make pathological diagnosis difficult; furthermore, the tissue obtained cannot be used for intraoperative frozen sections. Minimally invasive biopsy of breast nodules can obtain sufficient tissue for pathological diagnosis and for intraoperative frozen pathological sections.

\section{Aspects of Clinical Application of Ultrasound-Guided Minimally Invasive Biopsy of Breast Nodules That Need Improvement}

Minimally invasive biopsy can achieve complete resection based on imaging; however, it this not the standard procedure 

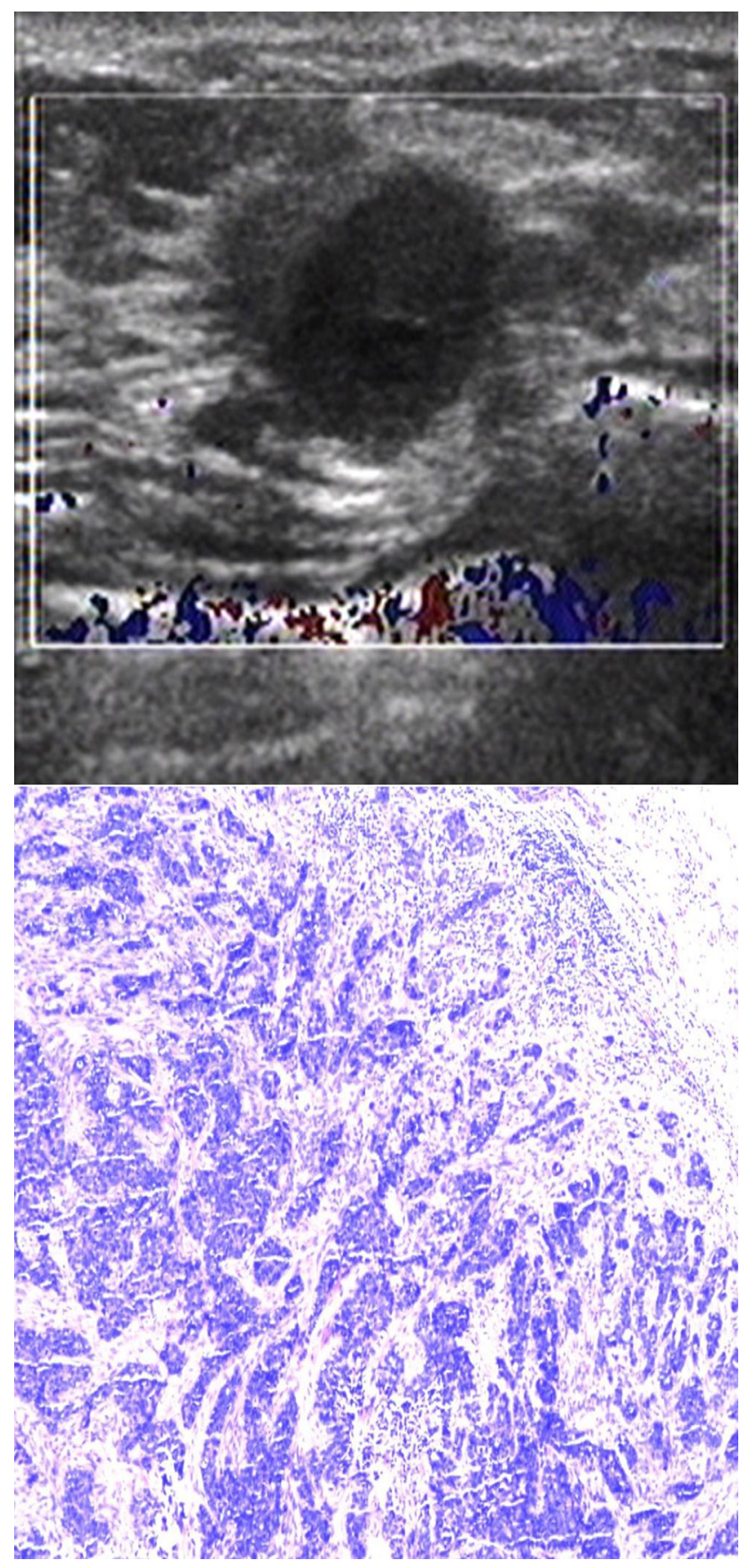

Figure 4 Color ultrasound examination of the breast revealing breast nodules of type BI-RADS 4A. Postoperative pathological results suggested invasive breast cancer, and gene detection suggested a low risk of recurrence; In this case, ultrasound-guided minimally invasive biopsy of breast nodules prevented use of chemotherapy.

for non-malignant tumor resection. The procedure for malignant tumors should be resection with tumor capsule in a residual-free manner. In a minimally invasive biopsy, the tumor is incised and aspirated into the tissue collection capsule using negative pressure. ${ }^{21}$ There may be residual cells or calcifications from tissues and cells. ${ }^{22,23}$
Minimally invasive biopsy is not suitable for patients with small breast thickness and those whose nodules are close to the skin, because the breast skin is easily injured during the operation. ${ }^{24}$ For patients who plan to breastfeed, minimally invasive biopsy of breast nodules should not be used in the area of the areola. Otherwise, it may cause tilting and retraction of the nipple and may increase the probability of acute mastitis during lactation. ${ }^{25,26}$

Bleeding during minimally invasive resection affects the quality of the ultrasound image in the surgical field and influences the judgment as to whether the nodule has achieved complete resection. ${ }^{27}$ The image quality of ultrasound equipment and the surgeons' level of expertise in ultrasound examinations also impact the quality of nodule resection. ${ }^{28}$ The tissue of breast nodule removed by minimally invasive biopsy is fragmented, and this is not conducive to general diagnosis of nodules and may affect the diagnosis of the rapid intraoperative frozen section. ${ }^{29}$

\section{Suggestions for the Clinical Application of Ultrasound-Guided Minimally Invasive Biopsy of Breast Nodules}

It is recommended that surgeons remove the nodules with membranes using traditional incision for patients with palpable breast nodules, unless the patient has a strong desire for a minimally invasive procedure. ${ }^{30}$ Minimally invasive biopsy is not recommended for breast nodules smaller than $0.7 \mathrm{~cm}$ unless there is strong evidence to consider malignant tumors. Non-palpable BI-RADS 3 breast nodules with diameters between $0.7 \mathrm{~cm}$ and $1 \mathrm{~cm}$ should be considered for minimally invasive biopsy. Non-palpable BI-RADS 4a nodules larger than $0.7 \mathrm{~cm}$ or non-palpable BI-RADS 3 nodules larger than $1 \mathrm{~cm}$ are recommended for minimally invasive biopsy. BI-RADS $4 \mathrm{~b}$ and higher-grade breast nodules should first be considered for traditional incision with membrane resection.

In summary, ultrasound-guided minimally invasive biopsy of breast nodules has unique value for clinical application. It is safe, less invasive, and affords rapid recovery. It can meet the needs of patients to remove nodules and to determine benign or malignant nature without affecting aesthetics. Non-palpable BI-RADS 3 breast nodules from 0.7 to $1 \mathrm{~cm}$ should be considered for minimally invasive biopsy. Non-palpable BI-RADS 4a nodules larger than $0.7 \mathrm{~cm}$ or BIRADS 3 breast nodules larger than $1 \mathrm{~cm}$ should be removed using minimally invasive biopsy. BI-RADS $4 \mathrm{~b}$ and highergrade breast nodules tend to be highly malignant, and should 


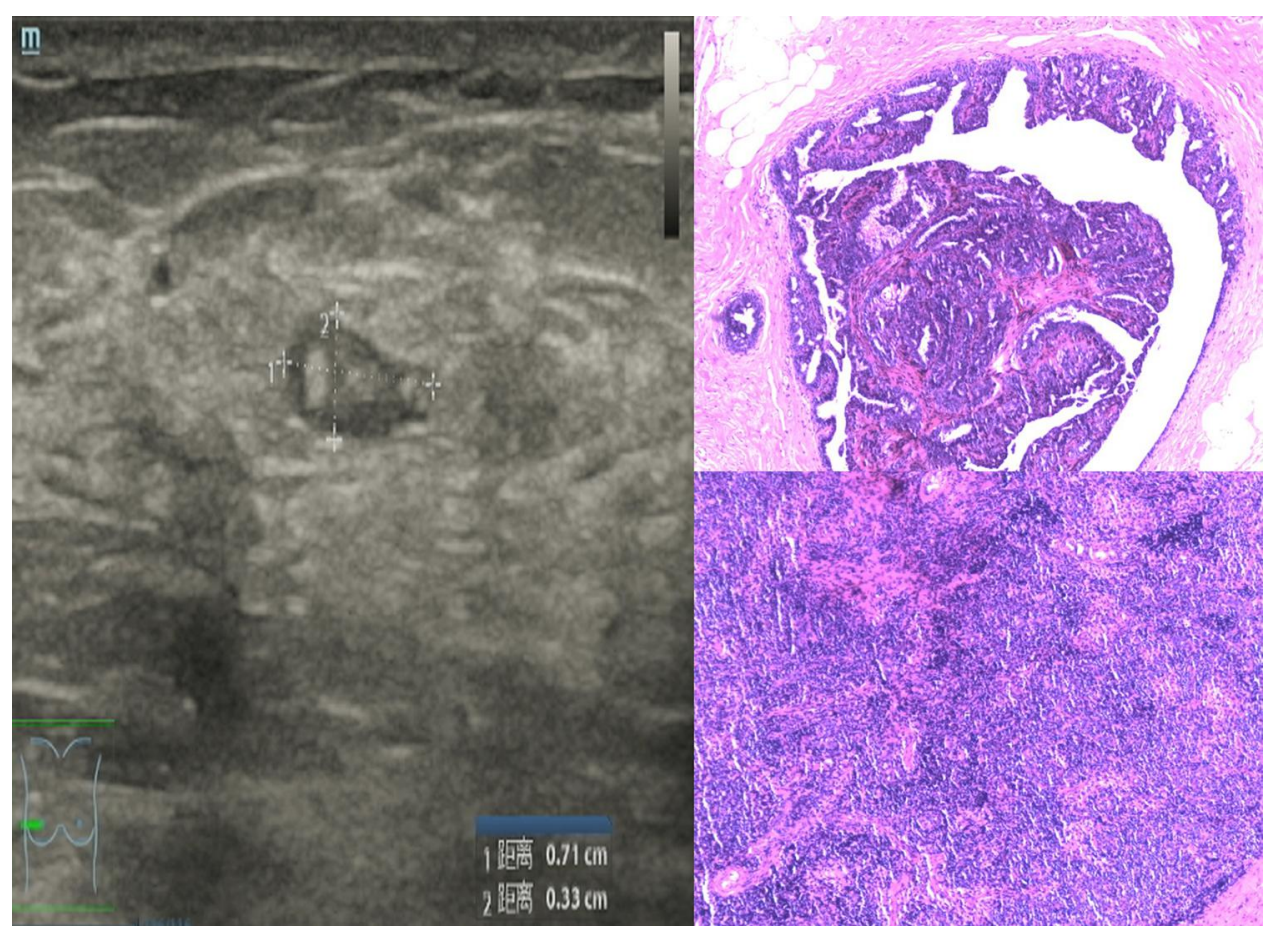

Figure 5 Color ultrasound examination of the breast revealing breast nodules of type BI-RADS 3. Postoperative pathological results suggested triple-negative ductal breast cancer, suggesting that high-risk BI-RADS type 3 breast nodules should also be considered for ultrasound-guided minimally invasive biopsy.

be diagnosed and treated, but not using minimally invasive biopsy. Minimally invasive biopsy has a wide range of advantages and is popular with women. Nevertheless, it should be selected for lesions of appropriate size and grade, and its misuse should be avoided.

This study had several limitations. First, this was a single-institution retrospective study. Second, the nodules in the minimally invasive group were all nonpalpable, unlike those in the surgery group. This introduces potential bias, and the results should be considered speculative rather than definitive.

\section{Ethics Approval}

This research complies with the guidelines for human studies and is in accordance with the Declaration of Helsinki. The Ethics Review Committee of General Hospital of Central Theater Command of the Chinese People's Liberation ArmyGH(WJ2019H113, Wuhan, China) approved the use of clinical data of these patients in this study.

\section{Informed Consent}

Written informed consent was obtained from all the patients for the publication. All the patients provided written informed consent to participate in this study.

\section{Funding}

The authors declare that they have received no external funding for this study.

\section{Disclosure}

The authors report no conflicts of interest in this work.

\section{References}

1. Monticciolo DL, Newell MS, Moy L, Niell B, Monsees B, Sickles EA. Breast cancer screening in women at higher-than-average risk: recommendations from the ACR. $J$ Am Coll Radiol. 2018;15(3Pt A):408-414. doi:10.1016/j.jacr.2017.11.034

2. Vourtsis A, Berg WA. Breast density implications and supplemental screening. Eur Radiol. 2019;29(4):1762-1777. doi:10.1007/s00330018-5668-8

3. Wu T, Sultan LR, Tian J, Cary TW, Sehgal CM. Machine learning for diagnostic ultrasound of triple-negative breast cancer. Breast Cancer Res Treat. 2019;173(2):365-373.

4. Susini T, Carriero C, Tani F, et al. Day surgery management of early breast cancer: feasibility and psychological outcomes. Anticancer Res. 2019;39(6):3141-3146. doi:10.21873/anticanres.13451

5. Chinese Anti-Cancer Association CBCS. Clinical practice guidelines in breast cancer by chinese anti-cancer association (2019 version). Chin Oncol. 2019;29(8):609-679.

6. Paepke S, Metz S, Brea Salvago A, Ohlinger R. Benign breast tumours - diagnosis and management. Breast Care. 2018;13(6):403-412. doi:10.1159/000495919

7. Liu S, Zou JL, Zhou FL, Fang YM. Efficacy of ultrasound-guided vacuum-assisted mammotome excision for management of benign breast diseases: analysis of 1267 cases. J South Med Univ. 2017;37 (08):1121-1125. 
8. Papathemelis T, Heim S, Lux MP, Erhardt I, Scharl A, Scharl S. Minimally invasive breast fibroadenoma excision using an ultrasound-guided vacuum-assisted biopsy device. Geburtshilfe Frauenheilkd. 2017;77(2):176-181. doi:10.1055/s-0043-100387

9. Hung WK, Ying M, Chan CM, Lam HS, Mak KL. Minimally invasive technology in the management of breast disease. Breast Cancer. 2009;16(1):23-29. doi:10.1007/s12282-008-0072-x

10. Thurley P, Evans A, Hamilton L, James J, Wilson R. Patient satisfaction and efficacy of vacuum-assisted excision biopsy of fibroadenomas. Clin Radiol. 2009;64(4):381-385. doi:10.1016/j. crad.2008.09.013

11. Bromberg SE, Moraes PRAD, Ades F. Prime incision: a minimally invasive approach to breast cancer surgical treatment - a 2 cohort retrospective comparison with conventional breast conserving surgery. PLoS One. 2018;13(1):e191056.

12. Kiran S, Jeong YJ, Nelson ME, et al. Are we overtreating intraductal papillomas? J Surg Res. 2018;231:387-394. doi:10.1016/j. jss.2018.06.008

13. Kibil W, Hodorowicz-Zaniewska D, Popiela TJ, Kulig J. Vacuumassisted core biopsy in diagnosis and treatment of intraductal papillomas. Clin Breast Cancer. 2013;13(2):129-132. doi:10.1016/j. clbc.2012.09.018

14. Bennett I, de Viana D, Law M, Saboo A. Surgeon-performed vacuum-assisted biopsy of the breast: results from a multicentre australian study. World J Surg. 2020;44(3):819-824. doi:10.1007/ s00268-019-05266-7

15. Eggemann H, Costa SD, Ignatov A. Ultrasound-guided versus wire-guided breast-conserving surgery for non-palpable breast cancer. Clin Breast Cancer. 2016;16(1):e1-6. doi:10.1016/j. clbc.2015.09.001

16. Huppe AI, Brem RF. Minimally invasive breast procedures: practical tips and tricks. Am J Roentgenol. 2020;214(2):306. doi:10.2214/ AJR.19.22082

17. He Q, Fan X, Guan Y, Tian J, Fan Z, Zheng L. Percutaneous excisional biopsy of impalpable breast lesions under ultrasound visualization. Breast. 2008;17(6):666-670. doi:10.1016/j.breast.2008. 08.004

18. Zhang C, Jiang D, Huang B, et al. Methylene blue-based nearinfrared fluorescence imaging for breast cancer visualization in resected human tissues. Technol Cancer Res Treat. 2019;18:1078161979. doi:10.1177/1533033819894331

19. Kell MR, Sharma S. Minimally invasive, maximal outcomes in breast surgery. Surgeon. 2016;14(3):174-178. doi:10.1016/j.surge.2015.06.006
20. Gallagher M, Jones DJ, Bell-Syer SV. Prophylactic antibiotics to prevent surgical site infection after breast cancer surgery. Cochrane Database Syst Rev. 2019;9:D5360.

21. Salazar JP, Miranda I, de Torres J, et al. Percutaneous ultrasound-guided vacuum-assisted excision of benign breast lesions: a learning curve to assess outcomes. Br J Radiol. 2019;92 (1094):20180626. doi:10.1259/bjr.20180626

22. Yom CK, Moon BI, Choe KJ, Choi HY, Park YL. Long-term results after excision of breast mass using a vacuum-assisted biopsy device. ANZ J Surg. 2009;79(11):794-798. doi:10.1111/j.1445-2197.2009. 05103.x

23. Merckel LG, Verburg E, van der Velden B, Loo CE, van den Bosch M, Gilhuijs K. Eligibility of patients for minimally invasive breast cancer therapy based on MRI analysis of tumor proximity to skin and pectoral muscle. Breast J. 2018;24(4):501-508. doi:10.1111/ tbj. 12984

24. Liu J, Huang L. Image-guided vacuum-assisted breast biopsy in the diagnosis of breast microcalcifications. $J$ Int Med Res. 2018;46 (7):2743-2753. doi:10.1177/0300060518770577

25. Liu S, Zou JL, Zhou FL, Fang YM. Efficacy of ultrasound-guided vacuum-assisted mammotome excision for management of benign breast diseases: analysis of 1267 cases. Nan Fang Yi Ke Da Xue Хиe Ba. 2017;37(8):1121-1125.

26. Patani N, MacAskill F, Eshelby S, et al. Best-practice care pathway for improving management of mastitis and breast abscess. Br J Surg. 2018;105(12):1615-1622. doi:10.1002/bjs.10919

27. Whitworth P, Schonholz S, Phillips R, et al. Minimally invasive intact excision of high-risk breast lesions and small breast cancers: the intact percutaneous excision (IPEX) registry. Ann Surg Oncol. 2019;26(4):954-960. doi:10.1245/s10434-019-07212-2

28. Tamirisa NP, Sheffield KM, Parmar AD, et al. Surgeon and facility variation in the use of minimally invasive breast biopsy in Texas. Ann Surg. 2015;262(1):171-178. doi:10.1097/SLA.0000000000000883

29. Bozzini A, Cassano E, Raciti D, et al. Analysis of efficacy and accuracy of 2 vacuum-assisted breast biopsy devices: mammotome and elite. Clin Breast Cancer. 2018;18(6):e1277-82. doi:10.1016/j. clbc.2018.06.014

30. Bevers TB, Helvie M, Bonaccio E, et al. Breast cancer screening and diagnosis, version 3.2018, NCCN clinical practice guidelines in oncology. J Natl Compr Canc Netw. 2018;16(11):1362-1389. doi:10.6004/jncen.2018.0083

\section{Publish your work in this journal}

Cancer Management and Research is an international, peer-reviewed open access journal focusing on cancer research and the optimal use of preventative and integrated treatment interventions to achieve improved outcomes, enhanced survival and quality of life for the cancer patient.
The manuscript management system is completely online and includes a very quick and fair peer-review system, which is all easy to use. Visit http://www.dovepress.com/testimonials.php to read real quotes from published authors. 